\title{
Smoldering Combustion Propagation on Solid Wood
}

\section{T. J. OHLEMILLER}

Building and Fire Research Laboratory

National Institute of Standards and Technology

Gaithersburg, Maryland 20899, USA

\section{ABSTRACT}

Factors controlling the spread of smoldexing combustion on solid wood (red oak, white pine) were examined in a configuration designed to enable self-sustained smolder. The sample was in the form of a U-shaped channel $74 \mathrm{~cm}$ long with $6.4 \mathrm{~cm}$ thick walls. A controlled flow of air was confined to the interior of the channel. Smoldering was initiated on the interior surface either of the upstream end of this channel (yielding forward smolder propagation), the downstream end (reverse smolder) or mid-length (coupled forward/reverse smolder). In separate tests the air flow velocity (referred to the initial cross section of the channel) was varied from about 9 to $22 \mathrm{~cm} / \mathrm{sec}$. At the low end of this range, the smoldering process was prone to extinction; at the high end it was increasingly likely to transition into flaming combustion. A simple energy balance model indicates a central role of radiative transfer in sustaining the smolder process.

Keywords: smoldering combustion, smolder propagation, wood

\section{INTRODUCTION}

Smoldering combustion of solid wood is a phenomenon which must be considered in the fire safety of wood structures and in the production of both energy and combustion products in wood stoves. Those aspects of this study most pertinent to wood stove combustion products are described in References 1 and 2; the present paper focuses on the smoldering propagation behavior of solid wood and seeks some insights into the factors controlling this process.

The spread of smoldering in various wood-based materials has been examined to varying degrees in the past. For example, Palmer [3] measured

Sponsored in part by the Department of Energy, Office of Buildings and Community systems. 
smolder spread rates in particle board and in sawdust; Ohlemfller [4] studied the smoldering behavior of cellulosic insulation, a modified form of shredded wood. In all previous work, the wood product had a greater permeability to oxygen diffusion than does solid wood; solid wood itself has apparently not been studied. The low permeability of solid wood forces the oxidation zone out near to the fuel's exterior surface where it is subject to substantial heat losses. As a result, a single flat, thermallythick slab of wood will not smolder unless the smoldex-derived heat is supplemented by an external radiant flux.

The goal here was to examine self-sustained smolder on solid wood; this precluded the artifice of an external heat flux. Instead the smoldering wood surface was made concave so that radiative interactions among elements of the surface allowed the possibility of stable smoldering; at the same time the configuration chosen allowed visual access for study of the smolder process. The quantitative results are probably configuration-dependent.

When smoldering is spreading over a fuel in the presence of a gas flow (here a controlled flow of air), the spread can be either in the same direction as the gas flow (called forward smolder), the opposite direction (reverse smolder) or a mix of the two. Previous studies revealed major differences in propagation behavior for permeable fuels [4]. Consequently, all three cases were examined here, to varying extent.

\section{EXPERTMENTAL APPARATUS AND PROCEDURE}

The wood configuration that was used is shown in Figure 1 . It is a flat bottom U-shaped channel; smoldering spreads along all three interior surfaces of the U. An observer looking into the open side of the $U$ has a good view of the smolder behaviox on the bottom of the $U$ and an oblique view of the other two surfaces. Note that the sides of the $U$ channel each consist of two pieces of wood $3.2 \mathrm{~cm}$ thick; the total thickness of each side is $6.4 \mathrm{~cm}$. Wood glue, plus a small number of wood screws, held the assembly together.

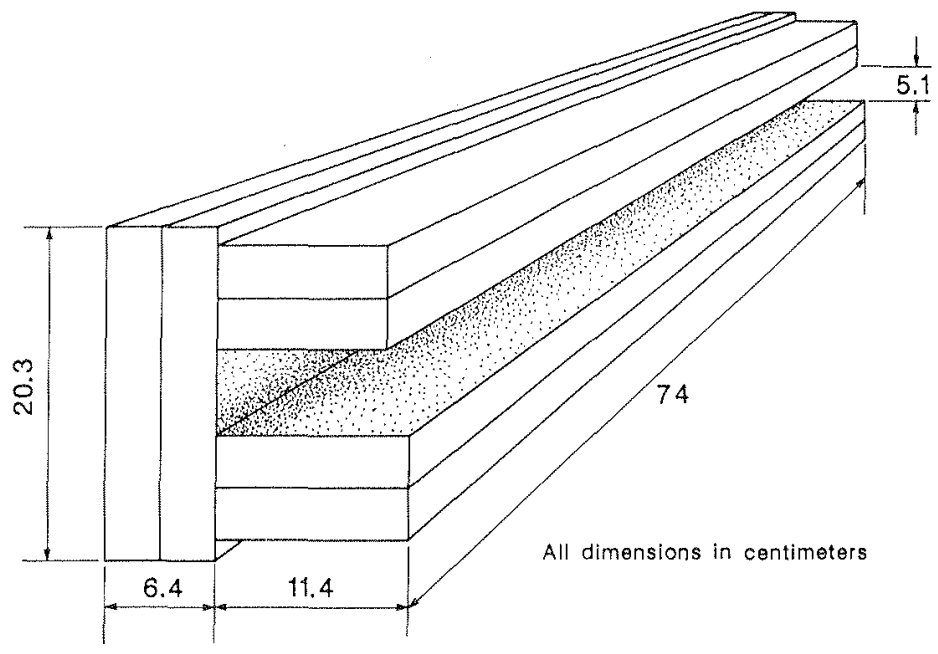

Figure 1. Configuration of wood sample. 
The wood sample (white pine in most tests) was enclosed in a steel chamber to provide for control of the flow of air and combustion products. The wood channel lay horizontally on one of its sides as shown in Figure 1 . All flow was confined to the channel defined by the inner wood surfaces. Visual access was provided by a series of five windows along the open side of the wood channel. Reference 2 has full details; it also has more complete information on the forward smoldering results and on exhaust gas analyses.

A constant flow of air at ambient temperature entered one end of the chamber; except for very mild turbulence in the upstream end of the channel the flow was laminar. The reported flow velocities here are based on the original channel cross-sectional area and the air flow rate at room temperature.

An electrically-powered igniter, $12 \mathrm{~cm}$. long, was used to start the smolder process at the desired position along the length of the channel. Placing the igniter fully upstream yielded forward smolder propagation; placing it fully downstream yielded reverse smolder. Mid-length placement yielded both modes, coupled to each other. The igniter was removed after the ignition interval (e.g., $1 \frac{1}{2}$ hours for pine). The rate of spread of the smolder reaction zone after ignition was followed visually for up to seven hours.

Information was obtained on the internal temperature profiles in the wood as the smolder reaction zone moved past the region of measurement. Nine thermocouples (chromel/alumel in $1.02 \mathrm{~mm}$ dia. stainless steel sheaths) were embedded in the bottom of the U-shaped wood channel, near its centerline, with the thermocouple leads parallel to the bottom surface. These thermocouples, although initially beneath the wood surface, provided a measure of the inner wood surface temperature as that surface receded past them. An aspirated thermocouple was used to measure gas temperatures in the channel in a small number of tests.

\section{RESULTS AND DTSCUSSION}

Overall behavior. During smoldering, the reacting surface of the wood char emitted an orange glow, which generally appeared uniform in brightness over the length of the oxidation zone (as much as $30-40 \mathrm{~cm}$ in length). The brightness of this glow depended on the air flow rate; at the lowest flow rates, it was necessary to darken the room for many minutes before the glowing could be discerned.

The smoldering process, once established, burned both inward into the walls of the channel and spread along the length of the channel. The inward burning caused the channel cross-section to open up as a function of time. Typically the cross-section went from its original rectangular shape to roughly circular with the top of the $U$ opening only slightly. Since the walls were finite in thickness, the inward burning had to terminate at some point; it tended to do so when the thinnest regions of the wall were about $1 / 2 \mathrm{~cm}$ in thickness. Since spread depends on heat transfer from the hot region behind the leading edge of the smolder front [2], termination of the inward spread could terminate the whole process, if the leading edge was close enough to the burn through region. 
Wood char invariably cracks as it is formed and consumed. The cracks had a noticeable influence on the propagation process mainly at the lowest air flow rates where the smoldering was marginal but they are probably responsible for the substantial scatter in the data seen throughout these tests.

The smolder spread process, as measured by the rate of movement of the smolder front along the channel, was generally nearly steady. In the small number of cases where this spread rate varied appreciably with time, the reported data are for the average rate exclusive of any early or late transients. The nearly steady behavior seen here may reflect the fact that, despite the long sample and multi-hour burn times, the overall smolder zone moved less than its own length during a test (for forward smolder).

Smolder propagation rate. The air inflow rate was varied from at or near the extinction limit to the flaming limit for both pure forward and pure reverse smolder propagation. The air velocity limits on these two smolder modes appeared to be very nearly the same and rather narrow.

Figure 2 shows the variation of the surface smolder propagation rate with air flow rate for forward smolder (propagation in the same direction as the air flow) on white pine and red oak. Stable, essentially steady, propagation was observed between about 8 and $22 \mathrm{~cm} / \mathrm{sec}$ air flow velocities. At the limits of this range smoldering could be sustained for an extended period of time (sometimes hours) but would eventually result in either extinction (at the low air flow end) or transition to flaming (at the high air flow end).

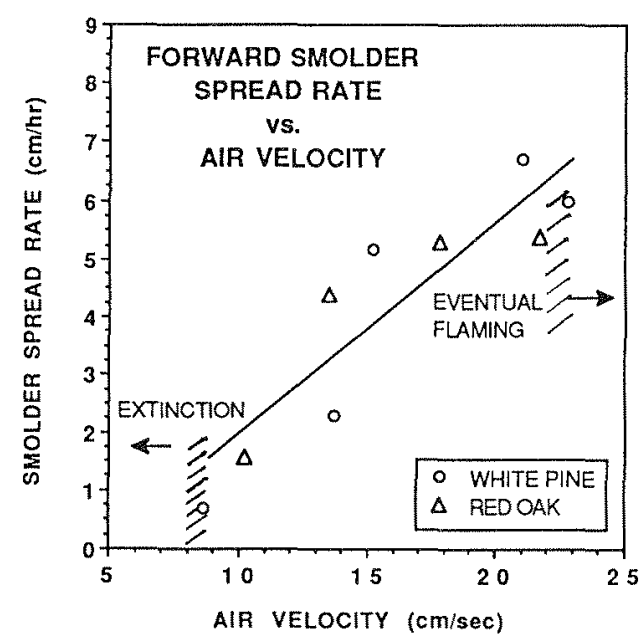

Figure 2. Forward smolder spread rate on white pine and red oak.

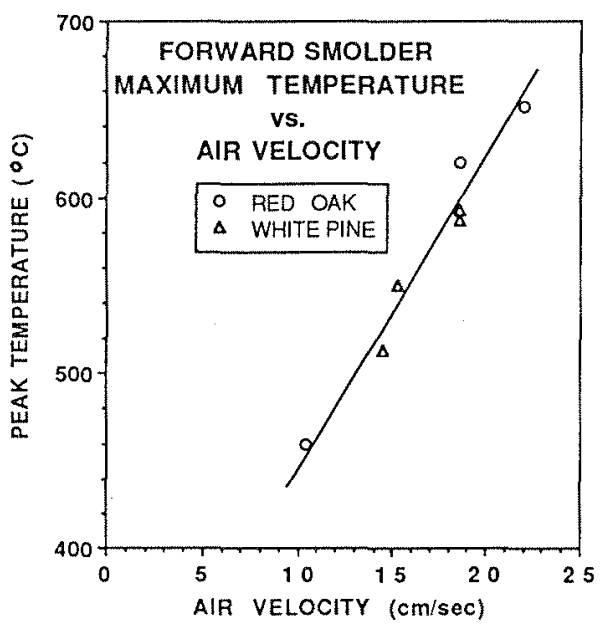

Figure 3. Peak surface temperature for red oak and white pine, forward smolder. 
Increasing smolder spread rate with increased air supply rate is consistent with the behavior of forward smolder in other configurations $[3,4]$. The increased flow of air accelerates the rate of transfer of oxygen to the wood char surface, hence the char oxidation rate, the local. heat release rate and thus the local temperature, thereby increasing the rate of heat transfer to unburned portions of the wood downstream and this causes the smolder front to move downstream more rapidly. Figure 3 shows that the char surface temperature does indeed increase substantially with increased air flow rate. A model below based on these qualitative ideas shows that it is difficult to explain the observed steepness of the temperature rise, however.

Smolder spread rates for white pine and red oak were essentially equal for a given air flow rate. In Reference 2, the thermocouple results from the forward smolder tests were used to estimate the rates of heat transfer from the combustion zone to the unburned wood downstream of it. (All estimates apply to the wood at the base of the U channel.) Heat conduction through the wood was found to be the least significant heat transfer mode; this nullifies the expectation that the higher conductivity of oak would yield more rapid spread. Radiation between the solid surfaces of the oxidizing char was shown to be the dominant heat transfer mode. Figure 3 shows the two types of wood to have equal peak surface temperatures in forward smolder, implying equal radiative transfer rates and thus equal propagation rates. Heat transfer rate, rather than an oxygen consumption limitation, was inferred to play a central role in smolder propagation rate in Ref. 2. The gas composition data in that reference reveal that there was always plenty of oxygen available at the leading edge of the forward smolder zone; the oxygen level there was 12 to 158 , depending on air flow rate. This does not preclude a key role for oxygen supply rate in the smolder propagation process since it influences the temperature of the radiating surfaces, as discussed in the model below.

For reverse smolder (propagation against the direction of the air flow), the variation of spread rate with air velocity was found to be more complex. Only white pine was measured; the results are shown in Figure 4. The same limits as for forward smolder were found for extinction and transition to flaming but, in between these limits, the spread rate shows a plateau. Figure 5 shows that this plateau in spread rate was accompanied by a plateau in peak surface temperature. Since radiation is again calculated to be the dominant heat transfer mechanism ${ }^{2}$ to the unburned wood, one can infer that the temperature plateau and spread rate plateau are closely related.

Note that, in reverse smolder propagation, convection cools the unburned wood while radiation (principally) and conduction through the wood heat it. This convective cooling of the leading edge has been invoked previously to help explain the weaker positive, or even negative, response of reverse smolder spread rate to increased air flow rate for two-dimen-

\footnotetext{
${ }^{2}$ While radiation is found to dominate in both forward and reverse smolder, the calculated total radiative transfer rate to the unburned fuel ahead of the reaction zone is twice as much for forward smolder for conditions where the measured smolder velocity is less than that in reverse smolder. This may reflect the rough nature of the heat transfer calculations which utilize the limited surface temperature data, however, it suggests that further study of heat transfer modes would be useful.
} 
sional spread in more porous fuels $[3,4]$. Here convection and radiation are coupled via the temperature distribution on the wall which is the source of radiative transfer. In reverse smolder convective cooling keeps the pre-heated wood region short $(5-10 \mathrm{~cm})$; in forward smolder, convective heating, starting from the moment the igniter is turned on ${ }^{3}$, causes a very extended pre-heated wood region (comparable to the sample length). It is plausible that, in reverse smolder, increased convective cooling in the wood pre-heat zone with increased air flow velocity acts to shorten the length of this zone and lessen the net radiative transfer while the increased supply of oxygen tries to increase the char oxidation temperature yielding the observed plateau.

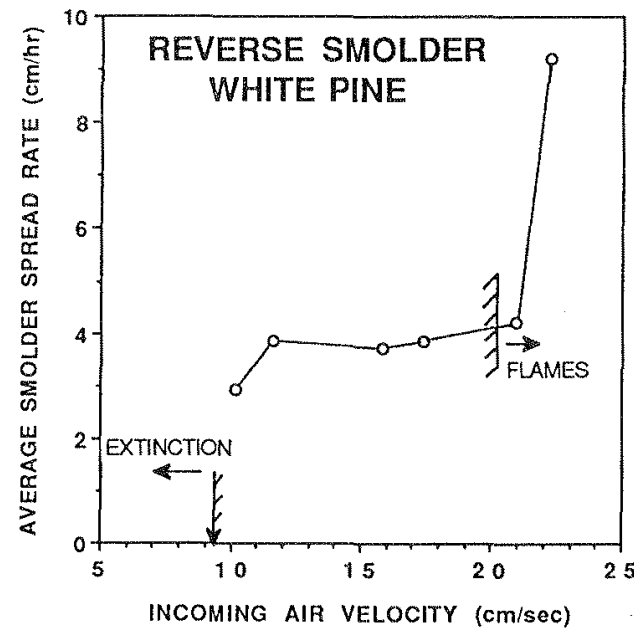

Figure 4. Smoldex spread rate on white pine in reverse smolder.

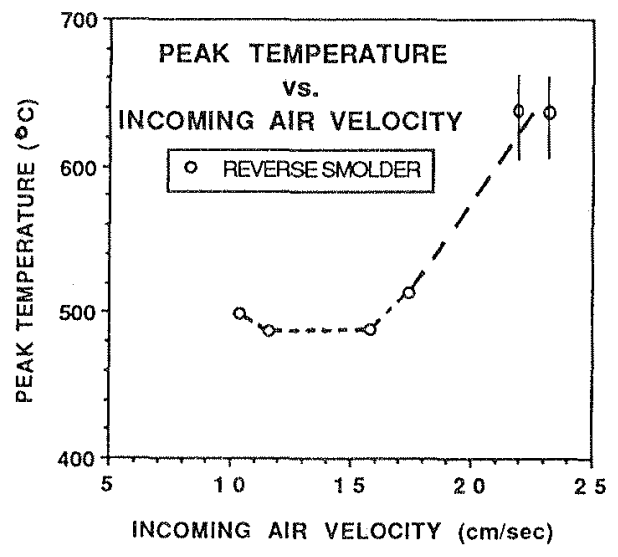

Figure 5. Peak surface temperature for white pine, reverse smolder. Points on right with error bars are approximate.

Only two fully-instrumented tests were run in the coupled forwardreverse mode (igniter placed midway along the channe1). The two propagation modes are coupled via radiative transfer (at least early in a test when the char oxidation zone is short and supplies heat in both directions) and via oxygen supply. Since the forward smolder zone is inherently downstream from the reverse smolder zone it gets only the depleted oxygen left from the reverse zone. If the reverse zone could grow to the length necessary to consume all of the oxygen, the forward zone would have to stop propagating. Since propagation depends on heat generation exceeding heat losses, the forward zone could be halted under less severe oxygen deple-

${ }^{3}$ Forward smolder retains the igniter's influence here; reverse smolder is influenced only early in the propagation process. The very high reverse smolder spread rate reported for $22 \mathrm{~cm} / \mathrm{sec}$ air velocity in Fig. 4 was measured over the relatively short period of 50 minutes after the ignition interval up to the time of transition to flaming. It may have been influenced by igniter pre-heating. 
tion, as we11. This did appear to happen during one of the mixed mode tests, even though the oxygen level in the exhaust gases never dropped below 148. When the reverse zone began to extinguish due to burn through of the wood, the forward zone resumed at a faster propagation rate than previously.

Flaming limit. Transition to flaming combustion was encountered at about the same air flow velocity $(20$ to $25 \mathrm{~cm} / \mathrm{sec})$ for both types of wood and for both forward and reverse smolder. The transition process was unpredictable as to its time of occurrence. It appears that it becomes an increasingly likely event as an air flow velocity of $20 \mathrm{~cm} / \mathrm{sec}$ is exceeded.

The transition process (i.e., the initiation of flaming in the gas phase) was typically associated with localized regions of greater than average char surface temperature. In Reference 2 it is shown that the average exhaust gas concentrations of $\mathrm{CO}(2-38)$ and total hydrocarbons (3/218) are below their flammability limits even at the elevated temperatures in the U-channel. Hydrocarbons need only reach $2.3 \%$ to be within the flammable limit, however, and it is quite probable that this degree of concentration can occur in the cracks in the char surface. Thus, most likely, it is temperature which limits the transition to flaming.

Surface energy balance. To gain some further insights into the relative roles of the various factors in these smoldering processes we construct a surface energy balance for a position on the char surface well behind the leading edge, at the bottom of the U-channel. The char here is exchanging radiation with the hot, oxidizing char on the side walls of the $\mathrm{U}$-channel and the cooler wall regions beyond. The oxidizing region of the char was noted to be up to $40 \mathrm{~cm}$ long; here it is assumed to extend equally in both directions (upstream and downstream) from the area of interest. It is also assumed to be isothermal and equal in temperature to the unit area on which we focus. This is consistent with the qualitative experimental observation that the brightness of the glowing char did not vary appreciab. ly with position. This unit area is also subject to convective cooling by the gas stream passing down the channel and to conductive cooling through the remaining wood thickness and the chamber wall behind it. Balancing these heat sinks against the char oxidation heat gives the following:

$h_{1}\left(T_{s}-T_{g}\right)+h_{w}\left(T_{s}-T_{a}\right)+\sigma(1-F)\left(T_{s}^{4}-T_{2}^{4}\right)=k_{m} \rho_{g}\left(Y_{o g}-Y_{o s}\right)\left(Q_{f} / h_{0}\right)$

Here the first term on the left is the convective heat loss to the gas flowing in the channel; $h_{i}$ is the heat transfer coefficient, computed from standard laminar tube flow correlations [5], $\mathrm{T}_{\mathrm{s}}$ is the surface temperature for which we want to solve and $\mathrm{T}_{\mathrm{g}}$ is the temperature of the gas in the channe1. The second term is a linearized conduction loss through the wood and includes also the two further series resistances in this heat loss path, conduction through the chamber wall and convective loss to the room air; $T_{a}$ is thus the temperature of the room air. The third term on the left is the net radiative loss from the unit area to its surroundings. Exchange with the cooler regions beyond the char oxidation zone is taken to be characterized by a single temperature, $\mathrm{T}_{2}$, substantially lower than $\mathrm{T}_{\mathrm{s}}$. The quantity $\sigma$ is the Stefan-Boltzmann constant; $(1-F)$ is the view factor with which the unit area sees these surroundings. The quantity $F$ is the view factor for the oxidizing char surfaces and is computed based on the original geometry (Fig. 1), though not, of course, the full channel length. 
An appropriate formula can be found in a standard text [6]. Even though the channel shape changes as the wood burns, the net view factor to the cooler surroundings changes very little since the top of the $U$ does not open up.

The char oxidation heat source, on the right, has been written in terms of the rate of transfer of oxygen from the gas stream to the char surface, multiplied by the reaction heat per gram of oxygen consumed $\left(Q_{f} / n_{0}\right)$. The quantity $k_{m}$ is the mass transfer coefficient, computed from a laminar correlation derived by analogy from the heat transfer correlation mentioned above [7]. The quantity $\rho_{8}$ is the density of the gas flowing in the channel and $Y_{o g}$ is its cross-sectional average oxygen mass fraction. The quantity $Y_{0 s}$, the oxygen mass fraction at the surface, must be eliminated. Assuming a thin, isothermal char oxidation layer where oxygen diffusion and reaction (first order in oxygen) compete, we infer the following relation.

$k_{m} \rho_{g}\left(Y_{0 g}-Y_{0 s}\right)=n_{0}\left(A_{v} Z\right) \rho_{c}^{b} \rho_{g} \exp \left(-E / R T_{s}\right) \int_{a}^{\infty} Y_{0} d x$

This equates the flux of oxygen through the boundary layer to the rate of consumption in the porous char. The quantity $\left(A_{v} Z\right)$ is the product of the reaction surface area per unit volume of char and the pre-exponential factor in the char oxidation rate expression. The quantity $\rho_{c}$ is the average char density in the reaction zone; $E$ is the activation energy of the char oxidation reaction and $R$ is the gas constant. Using an inferred exponential profile for $Y_{0}$ in the char oxidation layer one finds

$\mathrm{Y}_{\mathrm{os}}=\mathrm{k}_{\mathrm{m}} \mathrm{Y}_{\mathrm{og}} /\left(\mathrm{k}_{\mathrm{m}}+\gamma\right)$

where

$\gamma=\rho_{g}\left[D_{a c} n_{o}\left(A_{v} Z\right) \rho_{c}^{b}\right]^{\frac{1}{2}} \exp \left(-E / 2 R T_{s}\right)$

Here $D_{o c}$ is the effective diffusivity of oxygen in the pores of the char. Combining the above expressions we get the following form for the heat source term, which can be used in a $T_{s}$ calculation:

$\left(k_{m} Q_{f} Y_{o g} / n_{o}\right)\left[\gamma /\left(k_{m}+\gamma\right)\right]$

The energy balance thus provides a transcendental equation for the steady surface temperature of the oxidizing char. There is only one stable solution for parameter sets allowing a solution. Note that $h_{i}$ and $k_{m}$ are implicitly dependent on the flow velocity in the channel.

The above equations do not describe propagation, only the viability of steady char oxidation, but it is informative to compare solutions to the above equations with experiment. Table 1 shows the parameter values used in Fig. 6 which has typical results; the parameter $v_{8}$ in Table 1 is air velocity. The char oxidation kinetics are for a wood-based product, cellulosic insulation [8]. Note that only the product $D_{o c}\left(A_{v} 2\right)$ appears in the above equations; it comprises one adjustable parameter. The rate of heat release was always of the correct order $\left[\approx 1 \mathrm{~W} / \mathrm{cm}^{2}\right]$ for all cases where solutions existed, despite wide variations in this adjustable parameter. 
Table 1. Parameter sets used in Figure 6 (units are cgs)

\section{Parameter}

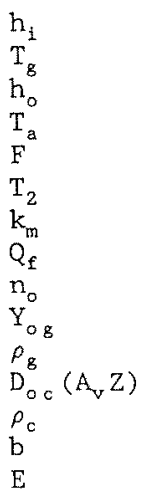

Set 1

(value at right) $/ 1.5$

$0.61 \cdot \mathrm{T}_{\mathrm{s}}$
$5.20 \mathrm{E}-5$

25

0.82

75

(value at right) $/ 1.5$ 4000

2.3

0.231

$0.354 / \mathrm{T}_{\mathrm{g}}$

0.030

0.12

1

$3.93 \mathrm{E}+4$
Set 2

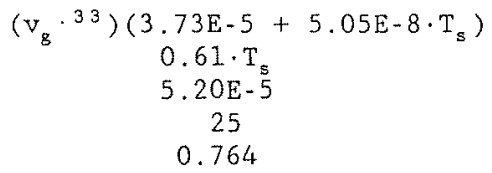

75

$\left(\mathrm{v}_{\mathrm{g}} \cdot{ }^{33}\right)\left(1.50 \mathrm{E}-4+1.74 \mathrm{E}-7 \cdot \mathrm{T}_{\mathrm{s}}\right)$

2.3

0.231

$0.354 / \mathrm{T}_{8}$

0.003

0.12

1

$3.93 E+4$

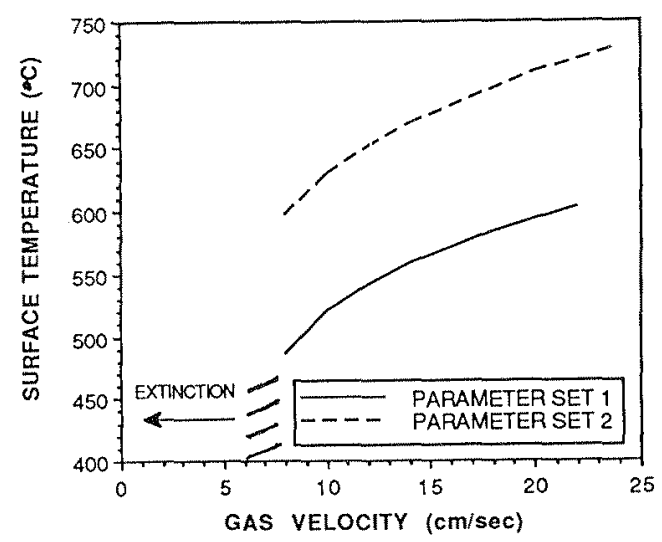

Figure 6. Calculated variation of char surface temperature with air flow velocity from energy balance model. Indicated extinction limit applies to both curves.

Extensive parametric studies of the solutions to the above equations were made. The extinction limits shown correspond to conditions where no steady solution exists; the quantitative agreement with experiment is not meaningful in light of the adjustable parameter noted above. For no set of parameters was the behavior of either forward or reverse smolder peak temperatures any more closely reproduced than is shown here. The predicted behavior seems intermediate between the two as regards the variation of temperature with air velocity. The model indicates a central role of radiative transfer in the ability of smolder to persist in these circumstances. The existence of solutions is quite sensitive to the value of the view factor, $F$; so also is the value of surface temperature achieved. 
This sensitivity suggests one possible source of departure between model. and experiment; the effective value of the view factor could easily be changing somewhat with air velocity (and smolder mode) since oxygen supply changes could cause variations in the char oxidation surface temperature distribution. That distribution was assumed uniform in the above model, based on visual observations; fairly subtle changes in the actual distribution could readily influence the net radiative loss rate.

\section{CONCLUSIONS}

Forward, reverse and mixed mode smolder over solid wood proceed at comparable rates and for comparable air flow ranges. Analysis of the heat transfer modes and of the balance of heat sources and sinks on the oxidizing char surface both imply a central role for radiative heat transfer in the self-sustaining of these smolder processes. Oxygen is always present in excess throughout the reaction zone and so both radiative heat transfer rate and oxygen supply rate appear to limit the rate of propagation. Oxygen supply rate interacts with heat transfer rate by influencing the temperature of the radiating surfaces.

\section{REFERENCES}

[1] Ohlemiller, T., Kashiwagi, T. and Werner, K., "Products of Wood Gasification", National Bureau of Standards NBSIR 85-3127, April 1985 .

[2] Ohlemiller, T. and Shaub, W., "Products of Wood Smolder and Their Relation to Wood-Burning Stoves", National Bureau of Standards NBSIR $88-3767$, May, 1988

[3] Palmer, K., Combust. Flame 1, 129, 1957

[4] Ohlemiller, T., "Forced Smolder Propagation and the Transition to Flaming in Cellulosic Insulation", National Bureau of Standards NBSIR $85-3212$, October 1985 .

[5] Bird, R., Stewart, W. and Lightfoot, E., Transport Phenomena, p. 399, Wiley, New York, 1960

[6] Eckert, E. and Drake, R., Analysis of Heat and Mass Transfer, p. 622 McGraw-Hill, New York, 1972

[7] Bird, R. Stewart, W. and Lightfoot, E., ibid, p. 645

[8] Rogers, F. and Ohlemillex, T., Combust. Sci. Technol., 24, 129, 1980 